\title{
Health behaviour, behaviour change and personalised diet: The concept of lifelong health
}

\author{
Zoltan Szakaly ${ }^{1 *}$, Karoly Peto ${ }^{2}$ \\ 1, 2 Faculty of Economics and Business, University of Debrecen, Debrecen, Hungary
}

\section{Keywords \\ Health behavior Behavior change Nutrition awareness \\ Personalized diet}

Received: 5 April 2018 Accepted: 7 May 2018

Published: 5 June 2018

\begin{abstract}
Health behavior is the totality of the types of behavior connected to health that are manifested in behavior created from health needs and health motives as an element of a healthy lifestyle. Staying in good health is influenced by a lot of factors. Regular physical exercise, a clean environment, reduced overwork, and a balanced diet have a prominent role. In the last twenty years, the authors have conducted many representative surveys to examine the Hungarian population's health behavior, nutrition habits, and sustainable lifestyle. According to research results, the consumers' interpretation of health goes beyond the classical organic-medical view: the several-dimension interpretation of health is becoming widespread. People are more or less aware of what they should do to stay healthy, but they do not act accordingly. That indicates that there is a significant difference between the importance of health-protective activities and their frequency in most cases. Some $48 \%$ of the respondents do not plan to change their present eating habits, which means that a significant population ratio has introverted and extremely passive behavior. As new technology and basic nutritional principle, personalized nutrition may create a good possibility to improve people's objective state of health, help change their way of life, and preserve lifelong health. But Hungarian consumers distrust and are uncertain about new technology despite its obvious benefits. To sum up, people must be supported to switch to a healthier lifestyle considering external conditions and needs.
\end{abstract}

(C) 2018 The Author(s). Published by TAF Publishing.

\section{INTRODUCTION}

Several studies have highlighted the significance of sustainable development $[1,2,3,4,5,6,7,8]$. [9] underlines merely three megatrends: environmental technologies, nano/biotechnology and healthcare, the key potential drivers for the next prosperity phase. At an environmental level, this is reflected in eco/organic/bio trends, of which market share has been steadily growing and in the advancement of nano and/or biotechnology, where the development of new materials and technologies reduces the need for raw materials and makes production more efficient by fostering new technologies. The third megatrend, which has become topical recently is health, related to population growth and longer life expectancy in developed countries, leading to ageing societies [10]. The megatrend of health comprises the holistic interpretation of health, preventive health behaviour and the concept of lifelong health. De- veloped economies have entered an era when human resources are not additional costs of economic development, but its pivotal driving forces. Their sustenance represents private, economic and social interest [7]. [11] suggests that the health industry will become one of the potential pillars of the 6th Kondratiev-cycle, becoming a major determining industry these days.

\section{A. Health Behaviour}

\section{THEORETICAL BACKGROUND}

Health behaviour is the totality of health-related forms of behaviour concerning the constructs of a healthy lifestyle that are attributable to a particular behaviour based on individual needs as a result of health motivations. [12] state that health behaviour consists of all behaviour forms that affect our health, as long as we are healthy. Others [13] suggest that health behaviour covers all activities performed by people to protect, promote or sustain their health inde-

* corresponding author: Zoltan Szakaly

†email: szakaly.zoltan@econ.unideb.hu 
pendently of their perceived health status and the objectivity of the judgement whether their behaviour is effective or not. Health-related behaviour is not merely a personal ef- fort, and it can also be considered as a good practice for self-regulation [14, 15, 16]. [13] reveal the following critical elements of health-related behaviour (Figure 1).

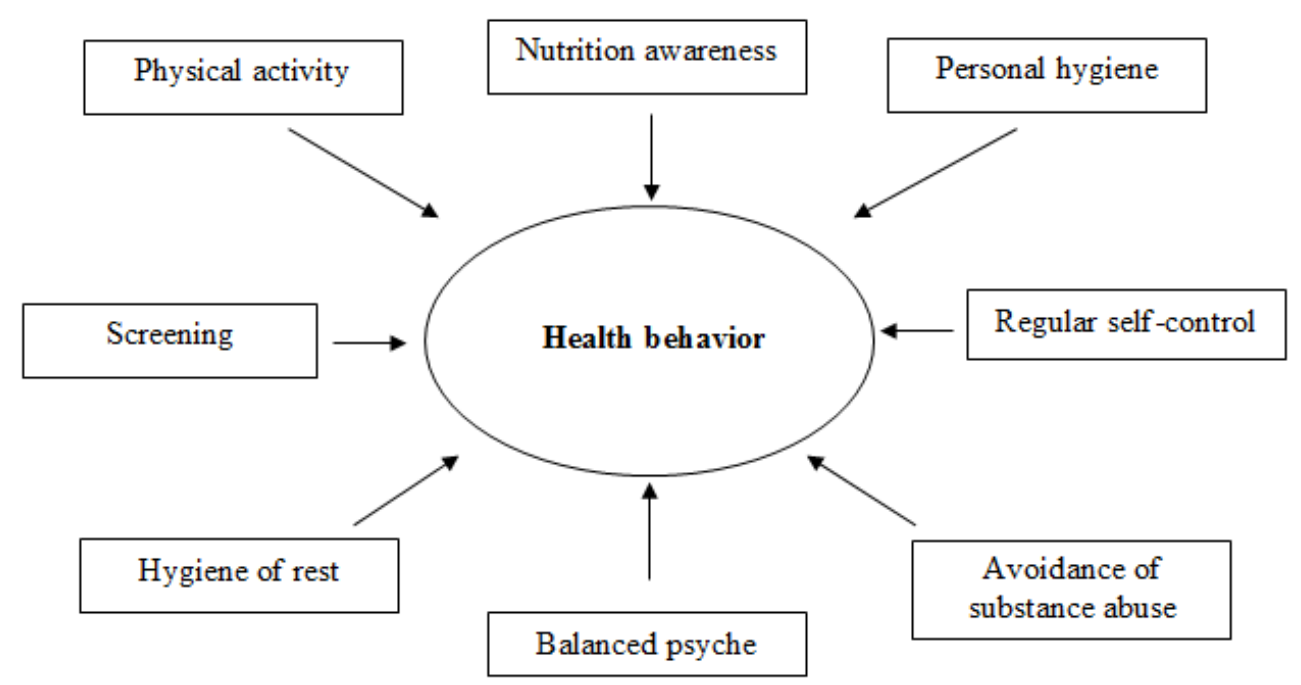

Fig. 1. Constructs of health behaviour (Source: [13])

\section{B. Nutrigenomics and Personalised Diet}

In the past three decades since deciphering the human genome sequence, genomic techniques and disciplines which use genomic methods underwent rapid development. In order to determine gene expression, genomic research attempts to reveal how the human genome interacts with environmental factors. The impact of nutrition, one of the key environmental factors is apparent on our health although this effect and its mechanism are poorly understood. Nutritional genomics or nutrigenomics, if the English designation is used, is a new science, which studies unknown relationships. Nutrigenomics helps advance the understanding of how human genes interact with dietary nutrients [17]. [18] argues that nutrigenomics studies the impact of nutrients at the genome level and embraces the application of genomic technology in food science and food technology.

Nutrigenomics has put a new light and focus on food science $[19,20]$, allows getting a much better understanding in comparison to the past how exposure to nutrients may raise the risk of diet-related diseases. Nutrigenomics is the key to understanding the variations of relevant individual sensitivity in relation to specific diet-related diseases. This science is establishing the development of personalised (nutrition) strategies for the advancement of evidence-based interventions to protect or to restore health. Personalised nutrition is the concept of adapting diets, food and nutrients to individual needs (genetic, lifestyle and environment) [21].
Personalised nutrition is a concept closely related to the concept of "one size fits all", which adapts specific product characteristics to individual customers, but the "customised" product will be mass produced and marketed.

\section{METHODS}

Over the past 20 years the author conducted several national representative questionnaire surveys assisted by his staff, and their primary goal was to investigate the health behaviour, nutritional habits and healthy lifestyle of the Hungarian population. The present study discusses the selected findings of previous consumer research.

To achieve the research objectives, questionnaire surveys were developed for mostly 1000 respondents and occasionally for 500 consumers. During the sampling, representativeness could already be taken as given in specific regions; therefore their structure fully complied with the quota established in advance by KSH (Hungarian Central Statistical Office) (quota sampling). In specific regions, the settlements were chosen by lot (simple random sampling). We used the process of random walk in the selected localities, and thus the appropriate respondents were selected entirely randomly. The next step was to choose the appropriate person for the interview out of the residents of the visited household by the so-called "birthday key" method.

As random sampling could not ensure representativeness in relation to the sample and the population, multidimensional weight factors were used to correct the samples in terms of gender and age. Following the correction, the sam- 
ples reflected the composition of the population in each case on the basis of four factors (region, type of settlement, gender and age).

\section{RESULTS AND DISCUSSION}

\section{A. Analysis to Explore the Health Interpretations of Hungarian Consumers}

An explanatory research conducted in 2012 interviewed consumers about their interpretation of the concept of health [17]. Their responses revealed a double level: on the one hand, the interviewees pointed out the lack of diseases (bio-medical approach), on the other hand, the constructs of a more complex bio-psycho-social model took centre stage. Subsequently, focus group investigations were used to analyze customers' knowledge of health dimensions [7], then the qualitative results were summarized and on this basis an eight-dimension dimension of health was constructed and then tested on a five-grade scale in the quantitative phase of our research [7, 17]. Research findings are summarised in Table 1.

TABLE 1

THE EIGHT DIMENSIONS OF HEALTH

\begin{tabular}{llll}
\hline \hline Dimensions & \multicolumn{3}{l}{ Statistical Indicator } \\
\cline { 2 - 4 } & Mean & Standard Deviation & Coefficient of Variation\% \\
\hline Physical condition & 4.62 & 0.690 & 14.9 \\
Good mental health & 4.58 & 0.704 & 15.4 \\
Mental clarity, active thinking & 4.54 & 0.740 & 16.3 \\
Emotional condition & 4.50 & 0.788 & 17.5 \\
Natural environment (e.g., ambient air, living environment) & 4.32 & 0.869 & 20.1 \\
Family and friendly relations & 4.31 & 0.930 & 21.6 \\
Infrastructure (good transport facilities, access to hospitals, schools) & 3.98 & 1.052 & 26.4 \\
Religion, spirituality & 3.48 & 1.443 & 41.5 \\
\hline \hline
\end{tabular}

To what extent do you think the following factors contribute to general good health? (1 - completely disagree, 5 - agree entirely) Source: [7], $N=1000$

The findings reveal that the physical, spiritual and intellectual dimensions are accepted mostly by the Hungarian population with relatively low standard deviation and coefficient of variation scores. It can also be concluded that consumers' health interpretation goes well beyond the classical bio-medical approach, i.e., the multidimensional interpretation of health is gaining increasing ground.

\section{B. Health Behaviour Study of the Hungarian Popula- tion}

1) Subjective perception of health: It is an internationally accepted fact that health perceptions are not closely re- lated to the actual health status (established by medical evidence), since self-assessment is significantly affected by social, economic and cultural factors, i.e., social layer, qualifications, job, income, residence (urban/rural) and various other factors.

GFK Hungary survey findings suggest that the subjective health perceptions of Hungarian population showed a deterioration in 2004-2011 [22]; and Eurostat database results reveal that a positive trend is emerging as of 2012 which is substantiated by our 2013 data (Table 2).

TABLE 2

HUNGARIAN CITIZENS' SELF-ASSESSMENT

\begin{tabular}{lll}
\hline \hline \multirow{2}{*}{ Response Categories } & \multicolumn{2}{l}{ Distributions of Responses } \\
\cline { 2 - 3 } & $\boldsymbol{N}$ & \% \\
\hline Excellent & 113 & 11.3 \\
Good & 526 & 52.6 \\
Medium & 289 & 28.9 \\
Bad & 58 & 5.8 \\
Very bad & 13 & 1.3 \\
"Do not know." & 1 & 0.1 \\
\hline \hline
\end{tabular}

All in all, how do you evaluate your health? Source: [17], $N=1000$ 
The table demonstrates that the Hungarian population as a whole is satisfied with its health status, "excellent" and "good" answers scored almost 65\%.

Our findings suggest that the perception of self-assessed health status can differ significantly from the realistic situation verified by statistical data is demonstrable for Hungary. Whereas respondents' self-assessed health can be considered fairly good; objective statistical data reflect a particularly poor health status [23]. We used the term "health gap" for the difference between objective and subjective (selfrated) health status. The difference represents the possibil- ity that the respondents are not aware of their actual health status, they deliberately conceal their existing diseases or ignore them.

2) The gap between recognition and action: However, the health gap observed in the Hungarian population has serious consequences. A person who is extremely satisfied with his/her health can also ask the following question: "If I am in good health, why should I do anything?" It may be the reason behind the marked difference between the significance and frequency of doing health-enhancing activities [24]. Table 3 presents the related data.

TABLE 3

THE GAP BETWEEN RECOGNITION AND ACTION

\begin{tabular}{|c|c|c|c|}
\hline \multirow[t]{2}{*}{ Health Enhancing Activity } & \multicolumn{2}{|c|}{ Performance of health-enhancing activity } & \multirow[t]{2}{*}{ The gap between significance and frequency, $\%$} \\
\hline & Significance $^{1}, \%$ & frequency $^{2}, \%$ & \\
\hline Satisfactory fluid intake & 92.7 & 80.5 & 12.2 \\
\hline Vegetable and fruit consumption & 90.9 & 64.4 & 26.5 \\
\hline Required amount of sleep & 89.7 & 56.7 & 33.0 \\
\hline Physical activity & 88.7 & 32.7 & 56.0 \\
\hline Stress avoidance & 88.3 & 37.4 & 50.9 \\
\hline Consumption of natural food & 73.5 & 31.8 & 41.7 \\
\hline Recreation, relaxation & 71.9 & 17.4 & 54.5 \\
\hline Social life & 61.7 & 15.4 & 46.3 \\
\hline Consumption of health-enhancing food & 53.3 & 13.7 & 39.6 \\
\hline Use of alternative treatments & 29.8 & 11.2 & 18.6 \\
\hline Consumption of dietary supplements & 29.8 & 9.7 & 20.1 \\
\hline Faith, prayers & 19.6 & 5.6 & 9.9 \\
\hline Meditation & 17.7 & 6.9 & 10.8 \\
\hline Yoga & 14.2 & 4.1 & 10.1 \\
\hline
\end{tabular}

${ }^{1}$ Total percentage of "very important" and "important" responses. ${ }^{2}$ Total percentage of "every day" and “3 or 4 times a week" responses. Source: [24], $N=1000$

The results show that a particular part of the population has recognised the significance of activities affecting their health, but putting them into practice takes more or less time. Effective health promotion activities include a sufficient amount of fluid intake, vegetable and fruit consumption, the required quantity of sleep, physical activities and avoiding stressful situations. Despite this, merely the frequency of daily fluid intake is of high (80.5\%) standard, and the gap between recognition and action is only $12.2 \%$. It seems continuously more common that fruits and vegetables arrive on the tables of consumers, the $26.5 \%$ difference between the two values can be considered insignificant. A similar situation exists in the case of the required quantity of sleep, although the gap is to be reduced further. It appears that the major distinction is between the factors of mental health; the need for recreation and avoiding stressful situations has already been recognised, but the realisation of these activities is measurably behind (50-55\%). In the order of preference, the social dimension of health (social life) is in the mid-range; however, merely $15 \%$ of the respondents were active from this point of view. There is some cause for debate over nutrition awareness: the consumption frequency of healthy food is under $15 \%$, and the gap between significance and activity is almost $40 \%$.

\section{Behaviour Change in Nutrition Awareness}

The question arises, in which stage of behaviour change the Hungarian population is, with regard to the specific dimensions of health behaviour. We used the Transtheoretical Model to give consideration to the stage of consumers' transition to healthy diets [25], i.e., the number of people who reached the level of action and maintenance. The Transtheoretical Model divides human behavioural change into five stages [26]: Precontemplation, Contemplation, Preparation, Action and Maintenance. To get a better interpretation of data mention must be made that here we refer to consumer perception of healthy diets independently of the fact to what extent the given way of nutrition can be regarded appropriate from the viewpoint of nutritional science. Research findings are summarised in Table 4. 
TABLE 4

STAGES OF BEHAVIOUR CHANGE IN NUTRITION AWARENESS

\begin{tabular}{|c|c|c|}
\hline \multirow[t]{2}{*}{ Response Category } & \multicolumn{2}{|c|}{ Distributions of Responses } \\
\hline & $N$ & $\%$ \\
\hline $\begin{array}{l}\text { I do not intend to change my old habits } \\
\text { to an allegedly healthier diet. (Precontemplation) }\end{array}$ & 240 & 48.0 \\
\hline $\begin{array}{l}\text { I feel the need to change to a diet considered } \\
\text { healthier in my interpretation. (Contemplation) }\end{array}$ & 113 & 22.6 \\
\hline $\begin{array}{l}\text { In the coming one month, I will take steps (Preparation) } \\
\text { to change to a diet considered better in my interpretation. }\end{array}$ & 35 & 7.0 \\
\hline $\begin{array}{l}\text { I changed to a healthier diet in } \\
\text { the past six months. (Action) }\end{array}$ & 25 & 5.0 \\
\hline $\begin{array}{l}\text { I have been following a healthier diet for more than } \\
\text { six months, the chance of relapse (return to my old habits) is minimal. (Maintenance) }\end{array}$ & 87 & 17.4 \\
\hline
\end{tabular}

Source: [25], $N=500$

The results suggest that $48.0 \%$ of the Hungarian population will not adopt a lifestyle deemed better in the coming six months. Precontemplators place very little emphasis on behavioural development, as they are unmotivated by health campaigns and unaware of the consequences of their inactivity. $22.6 \%$ of the respondents see real incentive to change from old to a more conscious nutritional habit. The literature mentions people in this group as Contemplators, who have a propensity to weigh the costs and benefits of changing. The rate of the two least active groups is $70.6 \%$, which is extremely high. Merely $7.0 \%$ of consumers are ready to take action in the coming six months (Preparators), whereas an additional 5.0\% have already adopted a healthier diet (in their interpretation). It is comforting to note that nearly one-fifth of the Hungarian population (17.4\%) has made modifications in their lifestyles for more than six months, and the rate of relapse was minimal (Maintenance). Changes gradually become regular and commonplace for this group, and its members do not rely on constant reinforcement by their social environment.

\section{A Program for Lifestyle Changes: Nutrigenomics- based Personalised Nutrition}

Nutrigenomics-based personalised nutrition, as a new technological and nutritional principle, may offer good opportunities to enhance the objective health status of the population substantively to promote lifestyle changes, leading to lifelong health. Precisely for this reason, we sought to address those crucial psychological processes that lead to the acceptance of the new technology (product) and the development of positive consumer attitude. The underlying aim of our research was to identify and use a successful model ("recipe"), which is suitable to predict the probability of introducing a new functional food product in the market and also the issues hindering this process. In establishing the questionnaire, we used two literary sources closely related to our research. One of them is an excellent study by [27], which surveyed consumer attitudes based on a representative population study concerning genetic tests and personalised nutrition. The other study is associated with [28], a Dutch researcher, who analysed customers' reception of nutrigenomics-based personalised nutrition by using a theoretical model constructed by him.

As a first step, consumers were exposed to the concept of personalised nutrition, of which content was the same as that of a quote by [27]. Interviewers read out the following questions to the respondents: "The construction of genetic tests are expected in the future (e.g., saliva sample tests) to predict the actual risk of subsequent chronic diseases (e.g., diabetes type 2 or cardiovascular diseases), i.e., Your susceptibility rate to the given disease. To avoid any risk, there is now an opportunity to follow your personal diet with its best fit with Your genetic profile. It improves the quality of Your life and can prevent the development of chronic diseases characteristic of You. It is called a genetic test based personal nutrition profile."

The introduction of the concept will be followed by four statements related to their affinity of completing the genetic test, and the respondents were requested to choose the answers they strongly agreed with (Table 5).

The rate of those who would take genetic testing because they wish to follow a health-enhancing, personalised, genetically tailored diet $(16.0 \%)$ is very low. It reveals their commitment to preventive, personalised health behaviour. Slightly more than a quarter $(28.6 \%)$ of the respondents take an interest in the test findings only in general terms. However, $24.6 \%$ of them categorically refuse to do the testing, and $30.8 \%$ are sceptical about the new technology. Significant difference $(p<0.001)$ has been merely found among age groups (18-29 and 30-39 years old are more receptive to new technologies) and educational achievement (the rate of academic graduates who would do the testing is 
markedly higher in each case, $p<0.001$ ). The findings lend themselves to identifying the most suitable drivers to enhance consumer willingness to accept personalised nutrition. We used the RONTELTAP's theoretical model (2008) addressing consumer perceptions of personalised nutrition driven by consumer acceptance and fundamental psychological processes through which these effects are mediated (Figure 2).

TABLE 5

AFFINITY TO COMPLETE A GENETIC TEST AMONG THOSE INTERVIEWED

\begin{tabular}{lll}
\hline \hline Statement & Distributions of Responses \\
\cline { 2 - 3 } & $\boldsymbol{N}$ & $\mathbf{\%}$ \\
\hline I would do genetic testing, but only because I am interested in its result. & 143 & 28.6 \\
I would do genetic testing as I intend to follow a health-enhancing, personalised, genetically tailored diet. & 80 & 16.0 \\
I would not do genetic testing in any case. & 123 & 24.6 \\
I do not know whether I would do genetic testing. & 154 & 30.8 \\
\hline \hline
\end{tabular}

Source: [25], $N=500$

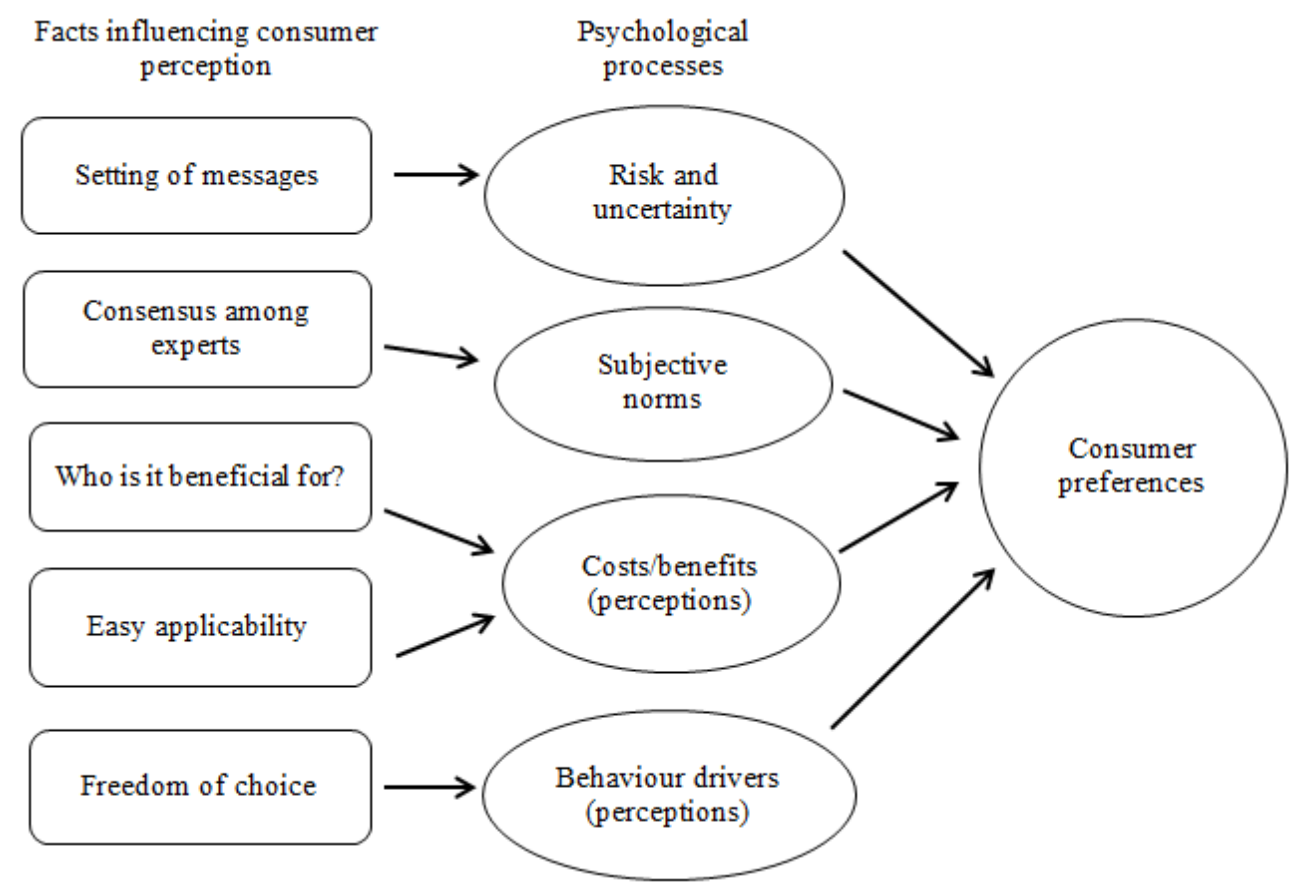

Fig. 2. Theoretical model: Enhancement of consumer preference regarding personalised nutrition (Source: [28])

We examined the facts influencing consumer perception by 11 statements. The answers were measured on a scale of 1-5, where 1 represented the lowest approval rating and five the highest one. The results obtained are demonstrated in Table 6.

Consumers with the highest mean value rated the option of free choice the highest (4.52), and $67.4 \%$ of them wholeheartedly agreed with this statement. The favourable mean value is combined with low standard deviation and coefficient of variation values. Fifty per cent of consumers (50.4\%) agreed that research should highlight the strengths and weaknesses of personalised nutrition (mean value 4.19). This statement can be interpreted as proof of con- sumer mistrust, but it can also serve as a basis for positive consumer preference. Moreover, in order to reinforce the above mentioned, the relatively high mean value (3.87) suggests that there should be a consensus among researchers regarding the benefits of the new technology. However, consumers express their clear and firm stance that they should benefit personalised nutrition (3.95) rather than researchers (3.05) or the food industry (2.88). It is considerably more accessible for them to accept a slight modification in their diets (3.83) than a massive change.

If the above findings are put into the conceptual framework of the model, we can get the optimised model of the acceptance of new health-promoting technologies (Figure 3). 
TABLE 6

ANALYSIS OF FACTS INFLUENCING CONSUMER PERCEPTION $(N=500)$

\begin{tabular}{|c|c|c|c|}
\hline \multirow[t]{2}{*}{ Statement } & \multicolumn{3}{|c|}{ Statistical Indicator } \\
\hline & Mean & Standard Deviation & Coefficient of Variation, $\%$ \\
\hline \multicolumn{4}{|l|}{ Setting of messages } \\
\hline $\begin{array}{l}\text { Personalised nutrition enables you to live } \\
\text { in good health as long as possible. }\end{array}$ & 3.48 & 1.249 & 35.89 \\
\hline $\begin{array}{l}\text { Personalised nutrition enables you to delay } \\
\text { the development of diseases and spend less time in ill-health. } \\
\text { Consensus among experts }\end{array}$ & 3.49 & 1.190 & 34.09 \\
\hline $\begin{array}{l}\text { It is an advantage if researchers fully agree } \\
\text { on the benefits of personalised nutrition. }\end{array}$ & 3.87 & 1.111 & 28.71 \\
\hline $\begin{array}{l}\text { Research should highlight the strengths and } \\
\text { weaknesses of personalised nutrition in detail. } \\
\text { Who is it beneficial for? }\end{array}$ & 4.19 & 0.986 & 23.53 \\
\hline $\begin{array}{l}\text { It would be desirable if I could prevent } \\
\text { diseases by a genetic test-based personal diet. }\end{array}$ & 3.95 & 1.101 & 27.87 \\
\hline $\begin{array}{l}\text { It would be desirable if the understanding of nutrition- } \\
\text { genetics interaction could offer benefits primarily for researchers. }\end{array}$ & 3.05 & 1.286 & 42.16 \\
\hline $\begin{array}{l}\text { It would be desirable if the understanding of nutrition- } \\
\text { genetics interaction could offer benefits primarily } \\
\text { for the food industry to develop special food products. } \\
\text { Easy applicability }\end{array}$ & 2.88 & 1.312 & 39.31 \\
\hline $\begin{array}{l}\text { I prefer to keep my old dietary habits and supplement } \\
\text { them with merely a few personalised products or dietary supplements. }\end{array}$ & 3.83 & 1.055 & 27.54 \\
\hline $\begin{array}{l}\text { I prefer to transform my earlier dietary habits. I will have to cut or to increase the } \\
\text { consumption of some food items. Also, } \\
\text { I need to fit an increasing number of new products into my diet. } \\
\text { Freedom of choice }\end{array}$ & 3.13 & 1.261 & 40.29 \\
\hline It is better if I can freely decide to choose genetic test based personal diet. & 4.52 & 0.817 & 18.07 \\
\hline It is better if the genetic test based personal diet is compulsory for everyone. & 1.91 & 1.274 & 66.70 \\
\hline
\end{tabular}

Source: [25], $N=500$

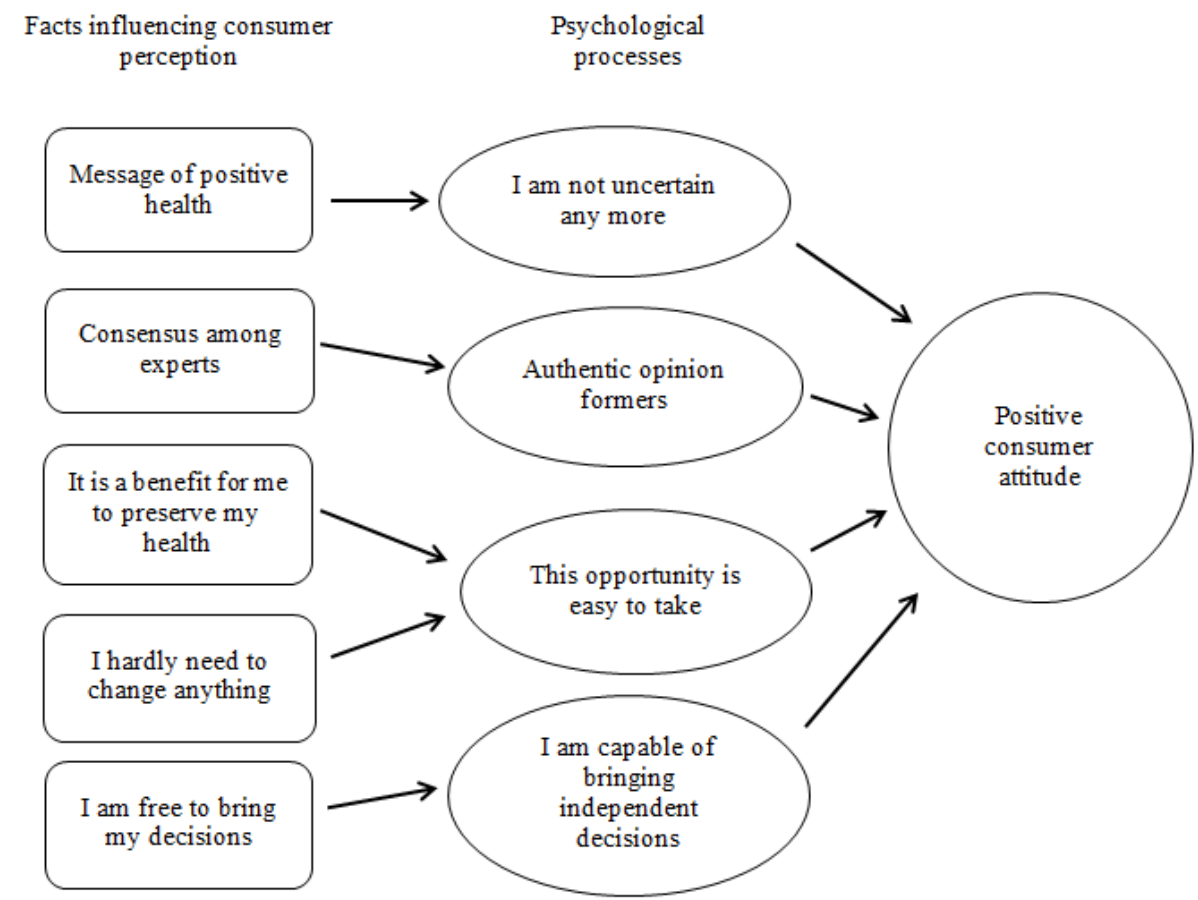

Fig. 3. Optimised model: Enhancement of consumer preference regarding personalised nutrition (Source: Authors' work based on [28] ) 


\section{CONCLUSION}

It can be concluded that the Hungarian population's health interpretation goes well beyond the classical bio-medical approach, i.e. the multidimensional interpretation of health is gaining increasing ground. The eight dimensions obtained in the qualitative examination (physical condition, state of mind, mental clarity, emotional life, natural environment, family and friendly relations, infrastructure, spirituality) can be broken down into five levels of significance and duly reflect the health concept of the Hungarian population. The five baseline dimensions [23] have taken on eight additional dimensions - natural environment, infrastructure and spirituality - by way of spontaneous statements. The novelty of the model is underlined by the fact that the eight dimensions we identified appeared in no other models.

Although on the level of information and interpretation the population has started to think of health issues in an increasingly complex way, it has not been verified by objective health status indicators. It is confirmed by the fact that respondents' self-assessed health can be considered fairly good, whereas objective statistical data reflect their particularly poor health status [23].

In most cases, there is a powerful difference between the significance and the occurrence of performing certain health-enhancing activities. It means that just like in the case of the multidimensional interpretation of health we are more or less aware of what we should do to preserve our health, but we fail to act accordingly. Consequently, the direct and indirect risks of inactivity should be communicated to the population. According to the Transtheoretical Model (TTM) of Behaviour Change, $48 \%$ of the respondents do not intend to change their current nutrition habits, i.e. the behaviour of about half of the population is closed-minded or explicitly passive. It draws attention to the differentiated application of programs supporting the transformation of our lifestyle and nutrition behaviour.

Nutrigenomics-based personalised nutrition, as a new technological and nutritional principle, may offer excellent opportunities to enhance the objective health status of the population substantively. However, research findings have revealed that Hungarian consumers are suspicious of and uncertain about the new technology despite its apparent benefits. This slightly positive attitude is likely to be due to the synergy of several factors. Traditional thinking, aver- sion towards novelty play a significant role in it, similarly to insufficient information and misperceptions about genetic testing. Consumers find the technology new to such an extent that we could find significant variations between socio-demographic segments in a few cases only, i.e. consumer preferences could not be grouped, and they showed a very high standard deviation. Consequently, the selection of target markets will be difficult or impossible. If we compare our findings with data from six European countries [27], it is evident that affinity to do genetic testing is the lowest in Hungary out of the studied countries.

The results obtained can be used in marketing communication targeting personalised nutrition. Our research suggests that consumers fail to differentiate between the messages of "live long in good health" and "live shorter in illhealth". Both deliver positive messages; if communicators still face a choice between them, they will focus on "health". Evidence-based research findings accepted by credible experts (e.g. physicians, researchers) in the related scientific field are essential for consumers. It is no coincidence that new health-promoting products are advertised with the "recommendations" of well-known professional organisations. The type of advantages and to whom the new technology can be offered are also important considerations. Consumers "save on their energy", they cannot change their habits easily. Therefore each solution that promises a better life quality through slight lifestyle modifications seems to be a successful concept. The desire for freedom and the right of independent decisions run very high in consumers. The survey findings reveal the biggest difference between the assessment of free will and the obligatory nature of recommendations. "You are the decision maker" type messages focus on these consumer needs.

As a result, the strategic task is to reduce the rate of uncertain consumers and to increase their willingness to purchase in the market of functional foods. An excellent example of this is the optimised model which can be used in practice, constructed to influence personalised nutrition-based consumer preferences according to Ronteltap's theoretical model. To summarize, the adoption of healthier lifestyles within the population is to be supported in any event, taking into consideration the external (motivating and hindering) circumstances (objective factors) and needs (subjective factors). 


\section{REFERENCES}

[1] Ayres RU. Statistical measures of unsustainability. Ecological Economics. 1996;16(3):239-255. doi: https://doi.org/ 10.1016/0921-8009(95)00091-7.

[2] Bosselmann K. The principle of sustainability: Transforming law and governance. London, UK: Routledge; 2016.

[3] Barnett ML, Darnall N, Husted BW. Sustainability strategy in constrained economic times. Long Range Planning. 2015;48(2):63-68. doi: https://doi.org/10.1016/j.lrp.2014.07.001.

[4] Gyulai I. Okologiai Intezet a Fenntarthato Fejlodesert Alapitvany; 2012. Available from: https://urlzs.com/5mS4p.

[5] Hodas D. The climate change convention and evolving legal models of sustainable development. Pace Environmental Law Review. 1995;13(1):75-96.

[6] Rex 00, Yetunde 0, Grace EC, Pearl OA. Sustainable urbanization: Investigating problems encountered in uncontrolled urban growth in Nyanya - A suburb of Abuja, Nigeria. International Journal of Humanities, Arts and Social Sciences. 2017;3(1):13-19. doi: https://doi.org/10.20469/ijhss.3.20003-1.

[7] Szabo S. The relationship of health-oriented nutritional habits and consumer behaviour [Unpublished Ph.D thesis]. University of Kaposvar, Kaposvar, Hungary; 2016.

[8] Teng F, Quoquab F, Hussin N, Mohammad J. Re-defining sustainable development values and its facets based on developing country perspective. Journal of Advances in Humanities and Social Sciences. 2016;1(2):1-13. doi: https: //doi.org/10.20474/jahss2.1.1.

[9] Allianz Global Investors. The sixth Kondratieff long waves of prosperity; 2010. Available from: https://urlzs.com/ $546 \mathrm{XH}$.

[10] Kristin B, Toshiko K. PRB projects world population rising 33 percent by 2050 to nearly 10 Billion; 2016. Available from: https://urlzs.com/BKwA9.

[11] Nefiodow LA. Langfristiger Megamarkt: Der 6 Kondratieff. Absatzwirtschaft. 1999;42(4):32-37.

[12] Baum A, Gatchel RJ, Krantz DS. An introduction to health psychology. New York, NY: McGraw-Hill; 1997.

[13] Harris DM, Guten S. Health-protective behavior: An exploratory study. Journal of Health and Social Behavior. 1979;20(1):17-29. doi: https://doi.org/10.2307/2136475.

[14] Ajzen I. Perceived behavioral control, self-efficacy, locus of control, and the theory of planned behavior 1 . Journal of Applied social Psychology. 2002;32(4):665-683. doi: https://doi.org/10.1111/j.1559-1816.2002.tb00236.x.

[15] Sungkhapong T, Prommete P, Martkoksoong N, Kittichottipanich B. The health behaviors' modification for controlling and prevention of diabetes mellitus by using promise model at premruthai pravate community Bangkok. Journal of Advances in Health and Medical Sciences. 2016;2(3):97-101. doi: https://doi.org/10.20474/jahms2.3.3.

[16] Suriah I, Fajarwati I. The application of behavior intention concept to analyze smoking behavior of employees post implementation of no-smoking area. International Journal of Health and Medical Sciences. 2015;1(3):51-56. doi: https://doi.org/10.20469/ijhms.30002-3.

[17] Szakaly Z. Health behaviour and conscious nutrition. In: 8th Nutrition Marketing Conference, Zamardi, Hungary; 2012.

[18] Biro GY. Nutrition and genomics: Mapping the health. Journal of Food Investigation. 2006;52(1):30-42.

[19] Mehrotra I. A perspective on developing and marketing food products to meet individual needs of population segments. Comprehensive Reviews in Food Science and Food Safety. 2004;3(4):142-144. doi: https://doi.org/10.1111/j. 1541-4337.2004.tb00064.x.

[20] Mutch DM, Wahli W, Williamson G. Nutrigenomics and nutrigenetics: The emerging faces of nutrition. The FASEB Journal. 2005;19(12):1602-1616. doi: https://doi.org/10.1096/fj.05-3911rev.

[21] Kussmann M, Fay LB. Nutrigenomics and personalised nutrition. Personalised Medicine. 2008;5(5):447-455. doi: https://doi.org/10.2217/17410541.5.5.447.

[22] Bernat A. Marketing and public relations; 2012. Available from: https://urlzs.com/2YNfw.

[23] World Health Organization. World Health Statistics 2016: Monitoring health for the SDGs; 2016. Available from: https: //urlzs.com/FoT8V.

[24] Szakaly Z, Szente V, Szigeti O. Functional foods [Unpublished master's thesis]; 2012. University of Kaposvar, Kaposvar, Hungary.

[25] Szakaly Z, Soos M, Polereczki Z. Consumer survey of healthy diet [Unpublished master thesis]; 2014. University of 
Debrecen, Debrecen, Hungary.

[26] Prochaska JO, Norcross JC, Diclemente CC. Changing for good: The revolutionary program that explains the six stages of change and teaches you how to free yourself from bad habits. New York, NY: W. Morrow; 1994.

[27] Stewart-Knox BJ, Bunting BP, Gilpin S, Parr HJ, Pinhao S, Strain JJ, et al. Attitudes toward genetic testing and personalised nutrition in a representative sample of European consumers. British Journal of Nutrition. 2008;101(7):982-989. doi: https://doi.org/10.1017/s0007114508055657.

[28] Ronteltap A. Public acceptance of nutrigenomics-based personalised nutrition. Exploring the future with experts and consumers [Unpublished Ph.D thesis]. Wageningen University, Wageningen, Netherlands; 2008. 